\title{
Epidemiology of death in the emergency department of a tertiary health centre south-south of Nigeria
}

\author{
*Ugare $\mathrm{GU}^{1}$, Ndifon $W^{2}$, Bassey IAE ${ }^{3}$, Oyo-Ita $\mathrm{AE}^{4}$, Egba RN ${ }^{1}$, Asuquo $\mathrm{M}^{1}$, Udosen $\mathrm{AM}^{1}$ \\ 1. Department of Surgery University of Calabar Teaching Hospital, Calabar Nigeria \\ 2. Dept. of Community Medicine, University of Calabar Teaching Hospital, Calabar Nigeria \\ 3. Department of Pathology University of Calabar Teaching Hospital, Calabar Nigeria \\ 4. Department of Community Medicine University of Calabar Teaching Hospital, Calabar Nigeria
}

\begin{abstract}
Background: The emergency department (E.D) of any hospital is an important entry point of critically ill patients. The initial management of these patients is often challenging, and for valuable lives to be saved, the in fracture and manpower should be up to date.

Objective: To analyze the epidemiology of death in our Emergency Department within 72 hours after admission, the death rate, and to establish any contributory factors.

Method: Demographic data, time of arrival at the ED, physical finding, the Glasgow coma scale(GCS), the injury severity score(ISS),the diagnosis, investigations done, treatment offered ,the time of death and the autopsy report, were entered into a Proforma. These data was analyzed using EPI-Info statistical programme version 3.4.3 of 2007.

Results: Four thousand and eleven (4,011) patients were seen in the E.D during the period. A total of three hundred and fifty five (355) mortalities were recorded. Their ages ranged from 4-87years, with an average of 34.5years. The male: female ratio was 2.1:1. The overall mortality in the hospital during the period was 859 : the E.D mortality figure representing $41.3 \%$. Fifteen patients were brought in dead. The 355 deaths fell into two categories: trauma and non-trauma. One hundred and forty-seven (41.4\%) persons died from trauma; road traffic accidents (RTAs) accounting for 118 (80.3\%). Two hundred and eight $(58.6 \%)$ persons died from nontrauma related causes, with chronic cardiovascular disorders been the most frequent cause of death 52[25.0]. Majority of the mortalities were between 26-50 years age range. 86.2\% of the mortalities presented late, greater than Ghours after the incidence. Within the 72 hours period, only $129(36.3 \%)$ were able to do the requested tests. Out of the 355 deaths, only 4[1.1\%] were autopsied. An in-hospital 72 hours death rate of 8.6 was recorded.

Conclusion: Road traffic accidents and cardiovascular disorders are the common causes of emergency death in UCTH.A recorded death rate of $8.6 \%$ is high, suspected contributory factors include systemic deficiencies such as the lack of a trauma system, prehospital care; late presentation, the role of chemist operators, traditional healers, and delayed referral systems. Key words: Epidemiology of death, emergency department, tertiary health centre.

African Health Sciences 2012; (4): 530 - 537 http://dx.doi.org/10.4314/ahs.v12i4.21
\end{abstract}

\section{Introduction}

The emergency department (E.D) of any hospital is an important entry point of critically ill patients. The initial management of these patients is often challenging, and for valuable lives to be saved, the in fracture and manpower should be up to date. This is because the morbidity and mortality in the E.D of any hospital is an indicator of the adequacy or otherwise of the state of clinical care and infrastructure ${ }^{1-3}$. In the developing world, there is

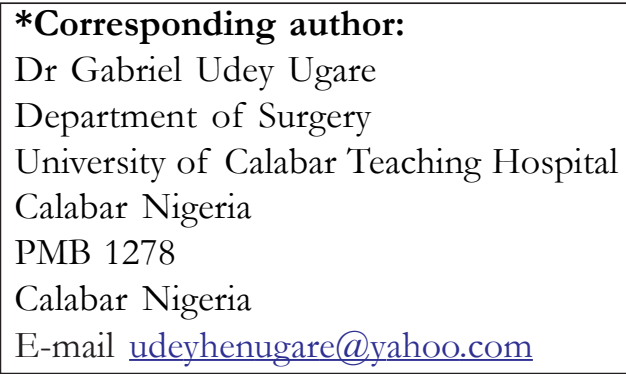

usually a paucity of skilled manpower in many clinical areas especially in trauma, as well as poorly equipped emergency units. These two factors, plus the poverty state of most patients, late presentation at the point of care, ignorance and the interference by untrained persons claiming to give medical care, often lead to most avoidable death ${ }^{2,3}$.

In general, mortality among traumatized patients has been related to the quality of pre-hospital care, the time lapse between injury and treatment, and type and extent of injury sustained ${ }^{4-6}$. Often majority of the traumatized patients are from road traffic accidents (RTAs) ${ }^{7-9}$ presenting with bony and soft tissue injuries ${ }^{10}$ which are beyond the comprehension and management skills most of the middle [untrained] men claiming to medical care.

The objectives of this analysis are to define the causes of death in the Emergency Department 
of our Institution within 72 hours of patient admission; type of injuries sustained by traumatized cases; and factors that may have contributed to death. We believe that such a study will provide essential information needed for hospital policy formulation, staff and infrastructural development, and public education.

\section{Methods}

This prospective observational study was carried out from October 2005 to September 2007, at the Emergency Department[E.D] of the University of Calabar Teaching Hospital[UCTH], a tertiary health centre South-south of Nigeria. The department is divided into two sections; a resuscitation bay, and wards for males and females. There is a minitheatre manned by senior Anesthesiologist resident and anaesthetic nurses that can handle minor emergencies such as incision and drainage, wound exploration, debridement and closure. Within the complex is a pharmacy shop that opens for 24 hours. There are also hematology, chemical pathology and microbiology laboratories that offer services for 12 hours during working days, and on call basis on weekends. The $\mathrm{x}$-ray department located within the same complex operates on the same modality. There is no intensive or critical care unit in the complex; patients requiring such service, usually those requiring organ support, are transferred by the ambulance to the old site of the hospital located about 4 kilometers within the city.

The Department is currently headed by an orthopaedic surgeon, for the reason that the hospital does not currently have a trained trauma surgeon supported by a team of general practitioners who are permanent staff of the department, and senior residents from various Departments undergoing mandatory posting in emergency medical care in preparation for various levels of their examination. He runs the day to day administration of the department, provide orthopaedic trauma services, as well as give clinical directives. Soft tissues, cardiothoracic, urologic, maxillofacial, and otorhinolaryngological traumas, are referred to general surgical and the respective specialist units.

Currently there are no dedicated traumas or medical emergency teams. The nursing staff operates on an eight hourly shift duty, and consists of emergency trained nurses at the senior and non emergency trained at the junior cadre. The support staffs consist of orderlies, cleaners, security personnel, and drivers. The ambulance service is for 24 hours throughout the week, but runs only intra- and interhospital services. The department does not have specialist trauma surgeons and emergency physicians. It lacks modern imaging facilities like magnetic resonance imaging (MRI) or computerized tomography (CT) scan, which are crucial for effective emergency services ${ }^{7,10}$. At the state level, there are no pre-hospital care services, nor a trauma system.

The patients used for the study, were those on admission in the E.D for least 72 hours. The 72 hours benchmark was chosen, because it allows time for adequate monitoring of progress and data collection. The patients were admitted after a detailed history and physical examination by the consulting E.D clinician. The details of the patients demographic data, types of injuries, time of incidence, time of arrival in the E.D, previous care at any peripheral hospital, GCS, and the injury severity score [ISS], in the case of trauma patients; this was estimated using the method described by Bull $\mathrm{JP}^{11}$, investigations done, treatment offered before death, and autopsy reports where it was done were entered into a validated Proforma. The data was updated on a 12 hourly basis. Patients who were treated and discharge, or refused admission were excluded from the study, as well as those who were brought in dead.

\section{Data analysis}

This was done using simple statistical methods to calculate averages and EPI-Info statistical programme version 3.4 .3 of 2007 to calculate median and mean values where necessary. 
A flow chart of the management structure of the Emergency department showing the flow of patients in the ED

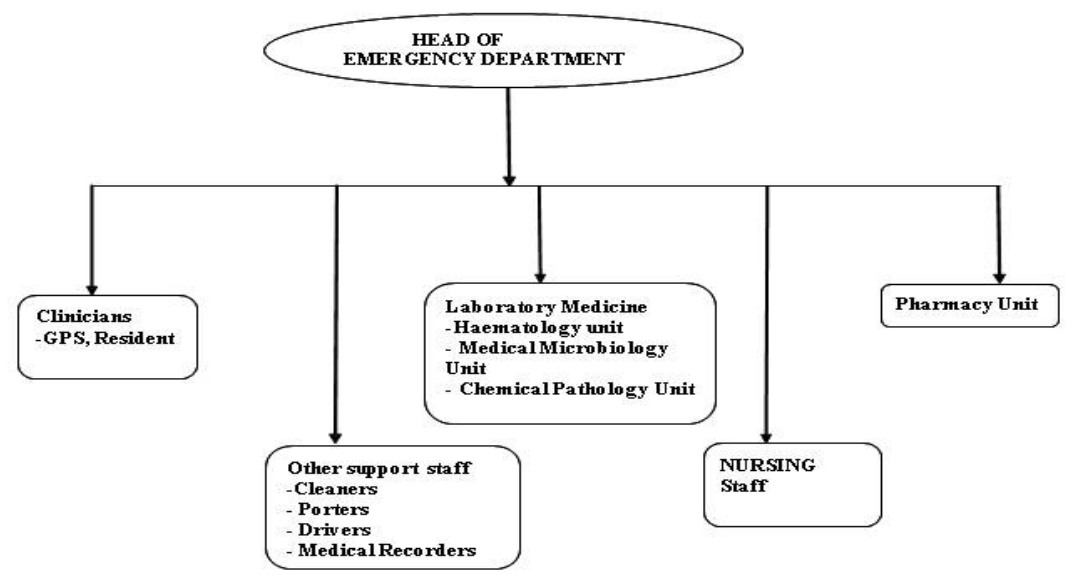

A chart showing the flow of patients in the Emergency department

A flow chart of the management structure of the Emergency Department

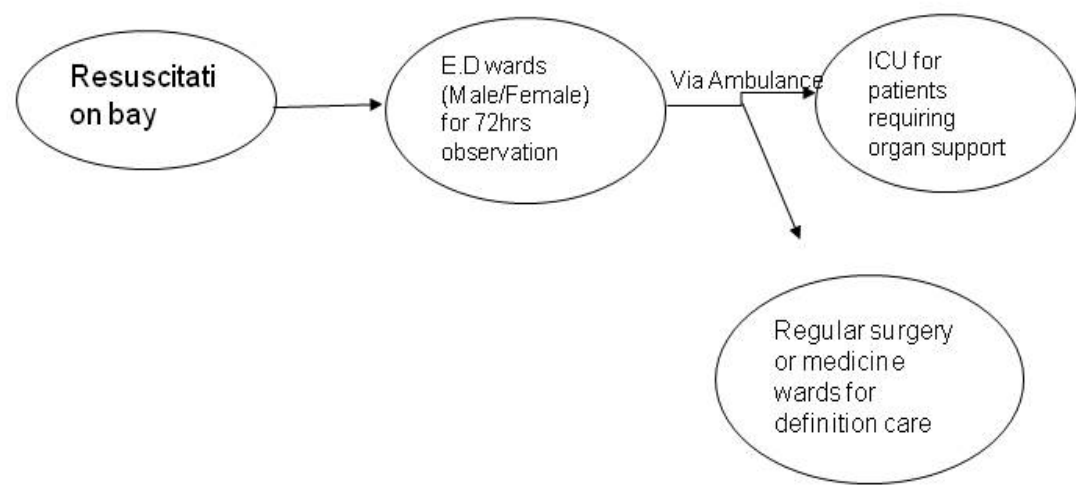

\section{Results}

Four thousand and eleven $(4,011)$ patients were seen in the E.D during the period. A total of three hundred and fifty five (355) mortalities were recorded. Their demographic characteristics are shown in table1. Their ages ranged from 4-87years, with a mean of $48.2 \pm 7.3 y e a r s$. The male: female ratio was 2.1:1. The overall mortality in the hospital (wards and E.D combined) during the period, was 859: thus E.D mortality figure represent 355/859 (41.3\%) of this. Fifteen (15) patients were brought in dead (BID), and were excluded from the study. The 355 deaths fell into two categories: trauma and notrauma, figure 1. Majority of the dead were people in the 26 to 30 year's age bracket. Head injury was an association in 54 [36.7\%] of trauma related death table 2. Fourteen [12.7\%] pedestrians were killed figure 3 , and a total $70[19.7 \%]$ of all the dead were unemployed, table1.

\section{Trauma death}

One hundred and forty-seven $(147 ; 41.4 \%)$ persons died from trauma. Their ages ranged from 4-62 years with a mean of $37 \pm 6.3$ years, the male: female ratio as $6.7: 1$. The ISS range was from $9-75$ with a median of 23.5 .Their GCS ranged from 6-15, with a median score of 6.1. Trauma victims were further categorized based on: type of injury sustained mechanisms of trauma and into passenger, pedestrian or rider, table 
2, figure 2, figure 3. Road traffic accidents (RTAs) accounted for $118(80.3 \%)$ of the deaths figure, with $106(89.8 \%)$ of these sustaining head injury table 2 . Thirty one $(21.1 \%)$ had had first aid before presentation; 19(61.3\%) in chemist shops, 7 (21.6\%) in a private clinic, and $5(16.1 \%)$ in a primary or secondary public health centre. The treatment given by these classes of care givers consisted of wound dressing, antibiotics, analgesic and tetanus toxin and intravenous fluids.

Table 1: Demographic characteristics of patients

\begin{tabular}{|c|c|c|}
\hline Occupation of patient & Cause of trauma death & Cause of non-trauma death \\
\hline Unemployed 70[19.7\%] & Road traffic accident $119[81.0 \%]$ & Cardiovascular disorders $52[25.0 \%]$ \\
\hline Civil servants $62[17.5 \%]$ & Assault $21[14.3 \%]$ & Metabolic disorders $20[9.6 \%]$ \\
\hline Traders 50[15.1\%] & Fall from height $5[3.4 \%]$ & Gastrointestinal disorders $3[11.1 \%]$ \\
\hline Students $44[12.4 \%]$ & Gunshot $2[1.4 \%]$ & Bacterial infections \\
\hline Retired civil servants $39[11.0 \%]$ & & $\begin{array}{l}\text { End organ failure (liver/kidneys) } \\
27[13.0 \%]\end{array}$ \\
\hline Cyclists $33[9.3 \%]$ & & Advanced malignancies $10[4.8 \%]$ \\
\hline Farmers $19[5.4 \%]$ & & Malaria $5[2.4 \%]$ \\
\hline Primary school pupil $13[3.7 \%]$ & & Drug reactions $2[1.0 \%]$ \\
\hline Motor vehicle drivers $8[2.3 \%]$ & & $\begin{array}{l}\text { Complication of sickle cell disease } \\
2[1.0 \%]\end{array}$ \\
\hline Teachers $5[1.4 \%]$ & & Complicated groin hernias $2[1.0 \%]$ \\
\hline Police personnel 4[1.1\%] & & Total $=208$ \\
\hline Clergy men $2[0.6 \%]$ & & \\
\hline Electricians $2[0.6 \%]$ & & \\
\hline Rubber tapers $2[0.6 \%]$ & & \\
\hline Hair dressers 2[0.6\%] & & \\
\hline Total $=355$ & & \\
\hline
\end{tabular}

Distribution of deaths by age and gender with a comparism between trauma and nontrauma[medical ] death

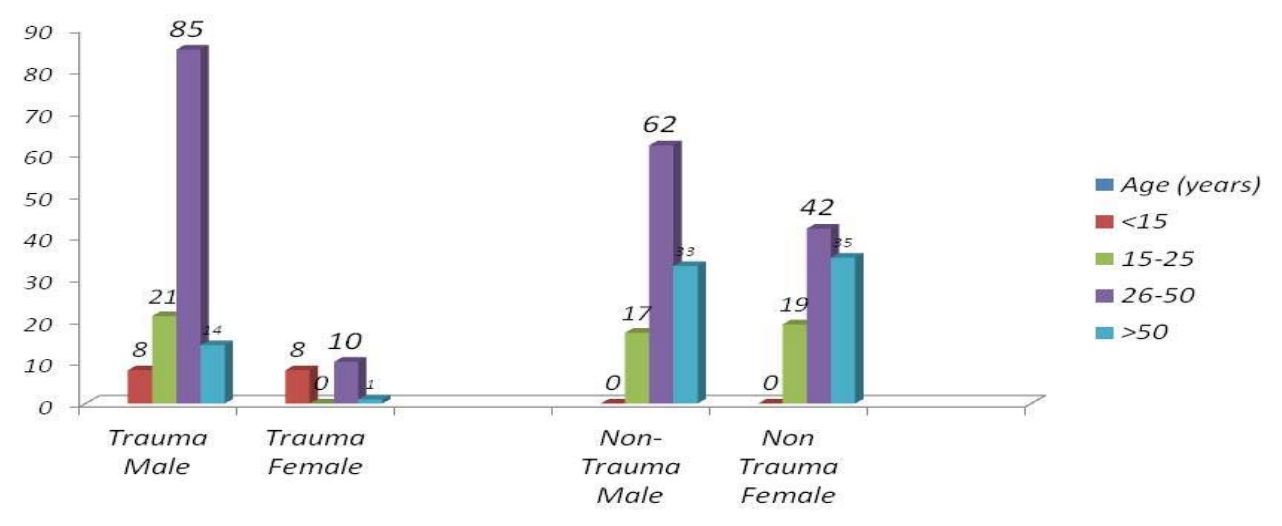

Figure 1: Age and sex distribution of patients with a comparism between trauma and non trauma death 
Table 2: Type of injury sustained by traumatised patients

\begin{tabular}{lll}
\hline Type of injury & Frequency (\%) \\
\hline Head and soft tissue [lacerations and aberrations] & $54(36.7)$ \\
Blunt head injury with associated fracture of lower limb bones & $31(21.1)$ \\
Blunt head injury only & $21 \quad(14.3)$ \\
Multiple knife cuts & $15 \quad(10.2)$ \\
Cervical spinal cord injury with quadriplegia & 5 & $(3.4)$ \\
Multiple fracture of lower limb bones & 5 & $(3.4)$ \\
Gunshot wounds & $2(1.4)$ \\
Fracture of facial bones + soft tissue injuries & $2 \quad(1.4)$ \\
Fracture of pelvic and lower limb bones & $2 \quad(1.4)$ \\
Blunt chest and abdominal injuries with haemoperitoneum & $3(2.0)$ \\
Fracture of pelvis, ribs and femur & $1(0.7)$ \\
Fracture of right femur, chest wall laceration and 11.0\% & $1(0.7)$ \\
superficial burn & \\
Fracture of right ulna + head injury & $3(2.0)$ \\
Crushed injury of lower limbs & $2(1.4)$ \\
Total & $\mathrm{N}=147(100.0)$ \\
\hline
\end{tabular}

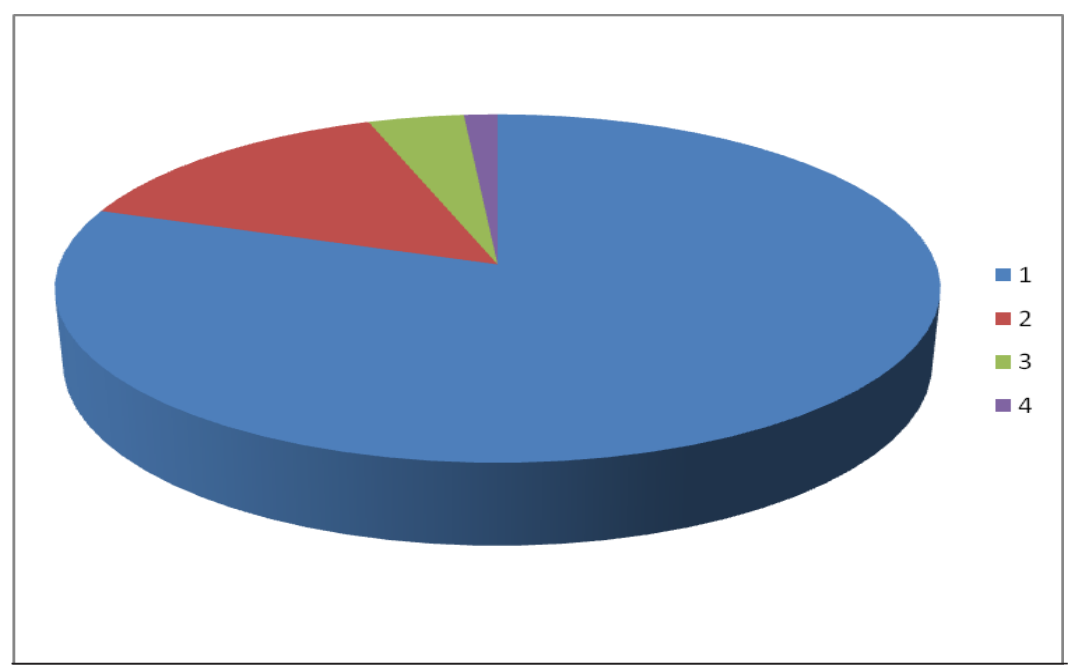

Trauma type

1.Road accident $\quad 80.30 \%$

2.Assault $\quad 14.30 \%$

3.Fall from Height $\quad 4.00 \%$

4.Gun shot $\quad 1.40 \%$

Figure 2 : Mechanism of trauma

\section{Time lapse before presentation}

\section{Trauma victims}

This ranged from 30 minutes -14 days, with an average of 3.2 days. Forty nine patients $(33.3 \%)$ presented within 6hours of the accident. These were mostly victims of accident that occurred within Calabar city; $37(75.5 \%)$ of these early presenters, were motor cycle accident victims. The rest of the patients presented outside the golden period [4-6 hours], having received first aid treatment in a chemist shop, a private clinic, a primary or secondary public health centre, where wound dressing, antibiotics and analgesics were often given. Most victims of trauma referred from clinics and public hospitals within and without the city arrived 3-7 days after the accident, sometimes in shock, with wound sepsis; without or with inadequate referral notes. 


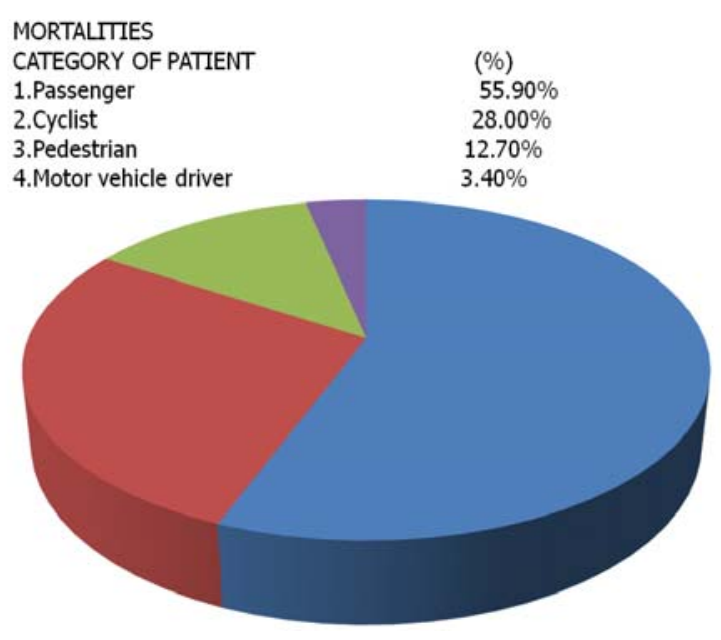

Figure 3 : Categories of trauma patients

\section{Non-trauma victims}

The time lapse between the onsets of the clinical problem to presentation at the ED varied from 4hours to 21 days, with an average of 5.3 days. One hundred and fifty one $(72.6 \%)$ of these emergencies have been seen by a doctor elsewhere, or treated in a chemist shop prior to presentation, with antimalaria, antibiotic, intravenous fluid , analgesic and haematinics.

\section{Investigations requested and done}

Most were basic investigations, such as full blood count (complete blood count), pack cell volume or urinalysis. Others such as electrolytes, urea and creatinine; fasting or random blood sugar level; Xrays and ultrasonography scan were requested based on the clinical situation. Within the 72 hours period, $129(36.3 \%)$ were able to do the requested tests. The tests most likely to be done within the period include $\mathrm{X}$-rays, ultrasonography scan, and blood sugar level. Some of the reasons why these tests were not done within this period included; delay in the laboratory due to absence of power, and lack of money to pay for the cost of carrying out the test.

\section{Discussion}

Our ED attends to patients in all specialties, except paediatric medical emergencies, that are seen in a dedicated paediatric unit outside the E.D. In our study, majority of the mortalities were medical 208 (58.6\%; table 1); and $25.0 \%$ were related to terminal cardiovascular diseases. This finding collaborated Ekere et al ${ }^{3}$, who also reported a majority of medical death $[79.8 \%]$ with $25.2 \%$ resulting from end stage cardiovascular diseases. This preponderance of medical death usually from end stage cardiovascular diseases has also been reported by other authors ${ }^{1,2}$, 12, 13. However, the report by Ofoegbu et al from Benin city Nigeria ${ }^{14}$, vary from this, as they reported $75.5 \%$ trauma related death in the E.D of the University of Benin Teaching Hospital and 24.6\% were medical death. This variation may not be satisfactorily explained by our study, but may be related to social factors like: violence level in the society, health awareness, poverty level and the level of industrialization. Ofoegbu and Afuwape reported higher incidences of gunshot wounds as well as some industrial injuries. We recorded only $2(1.4 \%)$ cases of death from gunshot wounds, with no death from industrial accident. Medical deaths in the $15-25$ years age range were related to infections and immunodeficiency syndrome (AIDS), while in the 26 - 50 years age range, death was from end stage cardiovascular diseases, metabolic disorders, and organ failure; in keeping with earlier findings $2,12,14$.

This study showed that traumatic death involved mainly people in the $3 \mathrm{rd}-5$ th decades of life, 95(64.6\%), which is in agreement with other authors ${ }^{1-3}$. This is the most active age group in any population, and their death constitutes an economic loss to families and the society ${ }^{3}$. Fifty-six percent of the patients spent up to 48 hours in the E.D before death; this $3^{\text {rd }}$ modal death is usually traceable to deficiencies in the health care service in terms of infrastructure and manpower, these deficiencies were noted during the course of this study. The resuscitation, organ support, monitoring and early 
intervention were lagging or lacking, heralding the onset of sepsis and organ failure, facts documented by Trunkey et al ${ }^{15}$ more than two decades ago.

The major source/mechanisms of trauma in our study was road traffic accidents, $80.3 \%$ (figure 2); similar findings had earlier been reported ${ }^{1-3,8,16}$. More than $60 \%$ of the patients, table 2, suffered head injury, which could not be properly defined due to the lack of imaging facilities like CT or MRI scan, and none had intensive care before death.

The median ISS was 23.5 which is high, but explained by the fact that the head, which carries the highest score, was the most commonly injured part of the body; involved in more than half of the victims. Forty nine $(33.3 \%)$ of the trauma patients presented within 4-6hours period following the incidence, which is the period most trauma victims can be successfully managed with good prognosis ${ }^{11,15,17}$. The death of this group of patients can only be attributed to the severity of injury or systemic failure in one way or the other. The average time of arrival in the E.D from the onset of the clinical problem was 3.2 and 5.3 days for trauma and nontrauma patients respectively. The intervention by traditional healers, chemist shops and poorly equipped and poorly staffed peripheral hospitals may have contributed in creating this delay in presentation. Late presentation is a well known independent factor for poor prognosis in trauma patients $2,3,58$. We had earlier reported on the negative effect of the activities of this set of unlicensed care givers ${ }^{18}$. However the role of ignorance and poverty cannot be ruled out; poverty may be a possible explanation why only $129(36.3 \%)$ of the patients performed the requested investigations.

We also recorded a male preponderance among the death, the ratio of male: female was $6.7: 1$ and 1.2:1 among the trauma and non-trauma death respectively. The high death rate among the male gender in the trauma group can be explained by the fact that men constitute the majority of the traffic on the road anywhere in the world ${ }^{19}$, a fact which has been documented by other authors ${ }^{1-3,7,8}$. The high incidence of road traffic accident and the associated death noted in this study could be attributed to a variety of factors: bad roads, ill informed or untrained drivers, lack of a trauma system and prehospital care, paucity of facilities for intensive care for severally traumatized patients even at the tertiary care centres, and the lack of ambulance services to evacuate trauma victims to a nearby health facility were basic emergency care can be offered.
These are lapses that if corrected can reduce trauma death, as noted in the developed world, currently put at $6-12$ per 100,000 population on the average 4,7,19. During the study, we observed that majority of the patients were brought into the E.D in private cars, taxis, trucks, and motor cycles. These forms of transportation are known to worsen outcome, especially in trauma patients $3,17,20,21$.

Our estimated death rate of $8.6 \%$ is high even by the standard of the developing countries. Investigators from other parts of the country Ajuwape et $\mathrm{al}^{14}$ and Ekere et $\mathrm{al}^{3}$ had $0.2 \%$ and $\%$ respectively. These two studies were however retrospective, with the possibility of incomplete data collection. The possible role played by neurosurgical services and imaging facilities like MRI and CT scan available in these centres, in lowering the death rate is also worthy of note.

We did not document anything suggestive of clinical incompetence nor management errors from the work force, due to work over lead, which McDermott et al ${ }^{17,22}$ reports that accounted for 68.0\% death in Australia among trauma victims. We suggest that, to reduce mortality in our E.D, there is an urgent need that the minimum in terms of infrastructure and man power be put in place. This will involve training or employing specialist trauma surgeons, emergency physicians, and the acquisition of modern imaging facilities like CT or MRI scan. At the state levels, there is an urgent need for the establishment of a trauma system, and pre-hospital care services. Such an investment will save our productive population from preventable /avoidable death.

\section{Conclusion}

Our documented death rate of $8.6 \%$ is high. This high death rate is multi-factorial: systemic deficiencies such as the lack of a trauma system, pre-hospital care; and facilities/manpower for investigating, monitoring, and intervention, as noted during the study. The patient related factors were; high poverty level and late presentation at the definitive care centre. The third factor is the role played by chemist operators, delayed referral system in primary, secondary and private health institutions and fourthly, the possible negative role by traditional healers and superstition which are not often obvious. 


\section{References}

1. Suigwe A. N, Ofiachi R. O. Mortality in the Accident and Emergency Unit of Nnamdi Azikiwe University Teaching Hospital, Nnewi: Patterns and factors involved. Nigeria Journal of Clinical Practice 2002; 5 (1): 61 - 63.

2. Adesunkanmi AR, Akinkuolie AA, Badmus O. S. A five year analysis of death in an accident and emergency room in a semi-urban hospital. West Africa Journal of Medicine 2002; 21(2): 99 104.

3. Ekere AU, Yellowe BE, Umune S. Mortality Pattern in the accident and emergency department of an urban hospital in Nigeria. Nigeria Journal of Clinical Practice, 2005;8(1):1418

4. Jarman B, Gaults, Awes B, Hider A, et al. Explaining difference in English Hospital death rates using routinely collected data. British Medical Journal 1999:318: 1515 - 1520.

5. Bentham G. Proximity to hospital and mortality from motor vehicle traffic accident. Soc. Sci. Med. 1986; 23 (10): 1021 - 1026.

6. Koval KJ, Cooley M, Cautu RV, Spratt KF. The effect of alcohol on in hospital mortality in drivers admitted after motor vehicle accidents Bull. NYU. Hosp. jt Dis. 2008; 66(1): 27 - 34.

7. Demetriades D, Murray J. Sinz B, Myles D, Chan L, Sathyaragiswaran L et al. Epidemiology of major trauma and trauma deaths in LOS Angeles country. J. Am. Call. Surg. 1998; 187(4): 373 383.

8. Solagberu BA, Duze AT, Ofoegbu CP, Adekanye AO, Odelowo EO. Surgical morbidity and mortality pattern in the accident and emergency room - a preliminary report. Afri. J. Med. Sci. 2000; 29 (3 - 4): 315 - 318.

9. Solagberu BA, Duze AT, Kuranga SA, Adekanye AO, Ofaegbu CK, Odelowo EO. Surgical emergency in a Nigerian University Hospital. Niger. Postgrad. Med. J. 2003 10(3) $140-143$.

10. Street SJ,Plank LD, Hill GL.Overview of modern management of patients with critical injury or severe sepsis. World J Surg 2000;24:67380

11. Bull JP.Injury severity scoring:In Alpar EK,Gosling P(Eds) Trauma :A Scientific Basis for Care $1^{\text {st }}$ Edition London: Oxford University Press 1999: 32-45

12. Cummings P. Causes of death in an emergency department. Am J Emerg Med 1990;8(5):379-384
13. Afuwape OO, Alonge TO, Okoje VM. Pattern of cases seen in the accident and emergency department in a Nigerian Tertiary Hospital over a period of twelve months. Niger. Postgrad. Med. J. 2007; 14 (4): $302-305$.

14. Ofaegbu CK, Odi T, Ogundipe O, Taiwo J, Solagberu BA. Epidemialogy of non trauma surgical deaths. West Afri. J. Med. 2005; 24 (4): $321-324$.

15. Trunkey DD. Trauma death. Trauma Sci Am 1983; 249(2): 28-35

16. Sorough AR, Ghahri-Saremi S, Rambod M, Malek-Hosseini SA, Nick-Eghbal S, Khaji A. Pattern of injury in Shiraz. Chin. J. Traumatol. 2008: 11(1): 8 - 12

17. Yates DW. Emergencies and Catastrophies In:Higgins NJO,Chisholm GD,Williamson RCN (Eds) Surgical Management 2nd edition Butterworth-Heinmann London ,1991:183-326

18. Udosen AM, Ugare UG, Ekpo R.Generalised tetanus complicating lower limb fractures managed by traditional bone healers. Tropical Doctor 2005; 35:237-239

19. Dalton AB, Epidemiology of accident In: Emin KA, Peter G. Eds. Trauma, a scientific basis for care. 1st edition, Arnold-London 1999: 1 - 19.

20. McDermott FT, Cordner SM, Tremayne AB. Evaluation of the medical management and preventability of death in 137 Road traffic fatalities in Victoria, Australia: an overview of the consultative committee on Road traffic facilities in Victoria. J. Trauma. 1996; 40(4): 520 $-533$.

21. Branas CC, Sing RF, Davidson SJ.Urban trauma transport of assaulted patients using non medical personal. Acc Emerg Med 1995; 2:486-493

22. McDermott FT, Cordner SM, Tremayne AB. Management deficiencies and death preventability in 120 Victoria Road Fatalities (1993 - 1994). The consultative committee on Road Fatalities in Victoria. Aus. NZ. J. Surg. 1997; 67 (9): $611-618$. 